\title{
Vivencia de la motricidad en las comunidades originarias Yanacona y Misak: hacia la configuración del tejido social y la identidad cultural
}

\author{
Experience of motor skills in the original Yanacona and Misak \\ communities: towards the configuration of the social fabric and cultural \\ identity \\ Experiência de habilidades motoras nas comunidades originais de \\ Yanacona e Misak: para a configuração do tecido social e identidade \\ cultural
}

Pablo Emilio Bahamón Cerquera Magister en educación desarrollo humano y valores

Docente Universidad Surcolombiana pabloemilio.bahamon@usco.edu.co Juan Carlos Cuéllar Santos Magister en educación Docente Universidad Surcolombiana juan.cuellar@usco.edu.co

Eivar Fernado Vargas Polanía

Maestría en educación. Área de profundización: diseño, Gestión y evaluación curricular

Docente Universidad Surcolombiana eivargaspolania@gmail.com

\section{Resumen}

El presente artículo es producto de la investigación denominada La motricidad humana: vivencia de las comunidades originarias Yanaconas y Misak en la configuración del tejido social y la identidad cultural, que se trabajó desde el enfoque cualitativo, apoyado en los tipos de investigación etnográfica y participativa. Aquí, se buscó la comprensión de las vivencias e interacciones motrices que han permitido configurar el tejido social y la identidad cultural en las comunidades originarias Yanacona y Misak que habitan en el departamento del Huila, con el fin de construir una propuesta de expresiones motrices fundamentada en la motricidad humana y la cosmovisión de las comunidades originarias en 
Colombia. En particular, se indagó sobre las expresiones motrices autóctonas, la incidencia y el aporte de éstas en la configuración del tejido.

Palabras claves: motricidad humana, comunidad originaria, tejido social, identidad cultural y expresiones motrices.

\section{Abstract}

This article is the product of a research project called La Motricidad Humana: vivencia de las Comunidades Originarias Yanaconas y Misak en la Configuración de Tejido Social e Identidad Cultural. This research project was based on the qualitative approach and supported on the types of ethnographic and participatory methodology.

This project tried to seek the understanding of the experiences and motor interactions that have enabled shaping the social fabric and cultural identity in the Misak and Yanacona indigenous communities that live in the department of Huila. This was performed in order to build a proposal based on the motor expressions supported in the human motricity science and the native communities' worldview in Colombia. In particular, this research project enquired about the native motor expressions, the impact and the contribution of these in building the social fabric.

Keywords: Human motricity, Native communities, Social fabric, Cultural identity y Motor expressions.

\section{Resumo}

Este artigo é o produto da pesquisa chamada motricidade humana: experiência das comunidades originárias de Yanaconas e Misak na configuração de tecido social e identidade cultural, que foi trabalhada a partir da abordagem qualitativa, apoiada pelos tipos de pesquisa etnográfica e participativa. Aqui, buscamos a compreensão das experiências e interações motoras que permitiram configurar o tecido social e a identidade cultural nas comunidades originais de Yanacona e Misak que vivem no departamento da Huila, a fim de construir uma proposta de expressões motoras com base em habilidades motoras humanas e a visão de mundo das comunidades originais na Colômbia. Em particular, foi questionada sobre as expressões motoras autóctones, a incidência e a contribuição delas na configuração do tecido.

Palavras-chave: motor humano, comunidade original, tecido social, identidade cultural e expressões motoras.

Entrando en contexto con la situación problemática, el presente texto plantea una postura crítica frente al discurso de la colonización occidental patrocinada por el imperio europeo, un discurso que se debe dejar de ver como un elemento natural en la evolución del mundo, para sentirlo como un mecanismo de penetración ideológica de carácter colonial, que ha tenido siempre como objetivo naturalizar las formas de vida 
europeas en el mundo y lograr así el control y dominio de los pueblos.

Es importante resaltar que en el departamento del Huila, Sur de Colombia, aún existen 10.335 originarios o indígenas, que sobreviven desde antes de la primera pisada de Cristóbal Colón hasta la actualidad. En este contexto las comunidades más representativas son la Yanacona y la Misak. Hay que destacar que las comunidades originarias del Huila continúan luchando por sobrevivir no solo como cuerpos, sino también, por la recuperación de su territorio, su cosmovisión y su cultura ancestral; lucha que se le debe apoyar desde el campo de la academia, mediante procesos investigativos.

Es por ello, que para el grupo de investigación Molúfode de la Universidad Surcolombiana, toma gran importancia acercarse a la comprensión de las formas de vivenciar la motricidad humana, es decir, las formas de sentir y vivir el mundo en estas comunidades; en sí, es "comprender al ser humano y su relación cotidiana con su mundo" (Trigo, 2005, p. 102) que, para este caso, serían los seres y el mundo de las comunidades originarias Yanacona y Misak. Este tema nos ha llevado a plantear el siguiente interrogante: ¿Cómo vivencian la motricidad humana las comunidades originarias Yanacona y Misak en la configuración de su tejido social y su identidad cultural?

En cierto sentido el proceso investigativo ayudó a fortalecer la lucha por el sostenimiento de las culturas de las comunidades originarias del Huila, desde la base de los postulados de la motricidad humana, en la que la identidad cultural fue el reconocimiento encarnado de las vivencias, ya que permitieron comprender desde la cosmovisión la integración, la inclusión, experiencia y las costumbres.

También se reconoció las formas de configuración y reconfiguración del tejido social e identidad cultural de las comunidades originarias del Huila, partiendo de la diversidad y la diferencia, de alimentar las fuerzas de lucha, ya no por un sobrevivir, sino por un vivir como originarios y sus formas de ser cultural en la búsqueda de validez e importancia de ésta, como de las otras existentes, "pues la diversidad cultural es una característica esencial de la humanidad, patrimonio común que debe valorarse, y preservarse, creando un mundo rico y variado, que acrecienta la gama de posibilidades y nutre los valores humanos, y constituye, por lo tanto, uno de los principales motores de desarrollo sostenible de las comunidades, los pueblos y las naciones" (Ministerio de Cultura, 2010, p. 371-383).

Es importante resaltar que mediante el proceso de investigación, se interpretó y se comprendió junto con los actores las vivencias e interacciones motrices, que han permitido configurar el tejido social y la identidad cultural en las comunidades Yanacona y Misak que habitan en el departamento del Huila. Además el contacto directo permitió construir colectivamente una propuesta de expresiones motrices fundamentada en la motricidad humana, que encarna la cosmovisión de las comunidades originarias en Colombia.

Teóricamente la investigación se fundamentó en la Motricidad Humana, teniendo en cuenta que es una teoría que ha tomado fuerza por ser una dinámica alternativa en las formas de educación, entendiéndola como espacio institucional y fenómeno vitalicio y esencial del hombre en su paso por la vida que aporta 
a la construcción colectiva y comunitaria. Se tiene en cuenta el planteamiento de Manuel Sergio cuando dice; "el movimiento humano intencional busca siempre la trascendencia" (KONMOCIÓN, Grupo de Investigación., 2008, p. 166). Desde esta perspectiva, se tuvo en cuenta las expresiones motrices como aspectos característicos de la Motricidad Humana.

Rubiela Arboleda define como "aquellas manifestaciones de la motricidad que se realizan con distintos fines: lúdico, comunicativo, estético, político, afectivo, de mantenimiento, de rehabilitación, de rendimiento, de salud, entre otros, organizadas siguiendo una lógica interna que establece un contexto social-cultural. Las expresiones motrices permiten acciones corporales, como: la danza, el teatro, los juegos, la aventura, las terapias, la diversidad de disciplinas deportivas y las prácticas ecológicas entre otras" (ARBOLEDA Gómez, 2008, p. 3).

Se trabajó desde el Tejido Social, el cual está asociado a todas las relaciones cotidianas que existen en una comunidad, desarrolladas por grupos y organizaciones que han configurado una subjetividad compartida y legítima. En este sentido, la configuración del tejido social tiene como principios la participación, la organización, la democracia, la autonomía y las relaciones de cotidianidad.

De otro lado, también se abordó el tema de las Comunidades Originarias, como un punto de referencia universal para entender el proceso histórico de las comunidades ancestrales de nuestra América. Hoy, son el resultado de la privacidad de la naturalidad en la que venían surgiendo, para convertirse en territorios subyugados y limitados a la posibilidad de evolución, siendo enmarcados en la categoría de conquista, desde la obtención del control de los territorios por parte de las naciones dominantes; sin embargo, luego de múltiples luchas de los pueblos indígenas, Latinoamérica ha obtenido el reconocimiento legal, político e incluso ideológico para remarcar su esencia ancestral.

Finalmente, encontramos este sendero enmarcado por la Identidad Cultural; la cual, fundamenta la comprensión y el trabajo a partir de la motricidad, las expresiones motrices y el tejido social con comunidades originarias, implicando la necesidad de interpretar, o por lo menos, tener un acercamiento al concepto de identidad cultural, que se enmarca en interpretaciones al pensamiento de Paulo Freire; de esta manera, se puede interpretar la identidad cultural como las características, ideas y formas de vida manifestadas por un grupo; esencialmente construido con base en la diferencia.

Para dinamizar la búsqueda investigativa y comprender la vivencia de las comunidades originarias, se aplicó el enfoque de investigación cualitativa, porque esta forma de investigar parte de un proceso de acción reflexiva que en este caso permitió comprender e interpretar críticamente junto con los actores, la vivencia de la motricidad y el tejido social en cada comunidad originaria seleccionada que habitan el departamento del Huila.

La utilización del enfoque cualitativo permitió integrar el tipo de investigación etnográfica y participativa, debido que es una "estrategia privilegiada para acceder a culturas diferentes, describirlas y 
comprender su modus vivendi" (LÓPEZ Parra, 2002, p. 90).

La investigación, se desarrolló a partir de los siguientes momentos:

Momento conceptual: se determinaron y se construyeron referentes conceptuales.

Momento Comprensivo: se asociaron las categorías a la situación problemática y al marco conceptual; además, se inició la aplicación de los instrumentos.

Momento interpretativo: se analizó la información recolectada por los investigadores, para ser compartida, dialogada, reconstruida y acordada con los líderes de las comunidades originarias; posteriormente se sistematizó, se cualificó.

Momento propositivo: se formuló una propuesta de expresiones motrices que contribuyó a rescatar y fortalecer la identidad cultural.

La población estuvo conformada por las comunidades originarias Yanaconas y Misak del departamento del Huila; y la muestra se seleccionó de manera intencionada, y estuvo representada por los resguardos indígenas Nuevo Amanecer (Guambianos), e Intillagta (Yanaconas).

Los resultados reflejan las vicisitudes de las comunidades originarias Yanacona, cabildo Intillagta y (Misak) resguardo Nuevo Amanecer, las cuales se presentan de acuerdo a las categorías comunidades originarias, cosmovisión, motricidad humana, y tejido social.

\section{Pueblo Yacona}

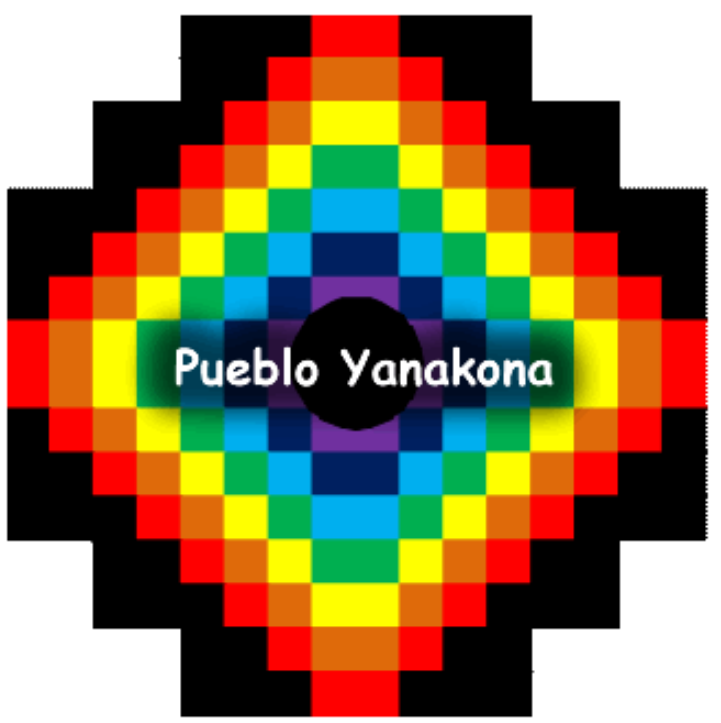

Varios estudios arqueológicos indican que la comunidad originaria Yanacona es una de las más antiguas de la cultura de Suramérica y Colombia, cuyos hallazgos se remontan a más de 3.000 años. Su territorio en el ámbito nacional se encuentra enmarcado en gran parte en el macizo colombiano.

El Pueblo Yanacona, como grupo indígena en este momento se halla distribuido en los departamentos del Cauca, Putumayo, Huila, Caquetá, Valle, Quindío y Bogotá. Su mayor población se encuentra ubicada en el departamento del Cauca, en el área hídrica del Macizo Colombiano. Ellos hablan español por ser un idioma impuesto por la colonización, pero tienen sus raíces lingüísticas en el Quechua.

Es de notar que los Yanaconas son un pueblo indígena que históricamente han resistido para sobrevivir; por eso, "el proceso de organización del Pueblo Yanacona busca la recuperación de su identidad como pueblo y de muchos aspectos valiosos de su cultura ancestral, como la cosmovisión, la recuperación de 
su lengua tradicional, el Quechua, el reconocimiento de su existencia y el fortalecimiento de sus autoridades de cabildo, como la Comisión Permanente Yanacona, y la Unidad Yanacona" (Ministerio de Cultura de Colombia, 2010, p. 8).

Anclado en el valle de Laboyos, en la inspección de Brúselas municipio de Pitalito, en la vereda Cabuyal, se encuentra hace aproximadamente quince años, ubicado el cabildo indígena Intillagta, grupo de personas que integran la comunidad originaria Yanacona, que vienen luchando por la recuperación de su territorio ancestral, su cultura y su identidad.

La vida de los Intillagtas como comunidad indígena campesina, gira en torno a la agricultura, siembra de cultivos como maíz, café, plátano, yuca, caña y diversos frutales. Además, en las épocas que no existe cosechas en su territorio trabajan como jornaleros en otras parcelas de la región. En este sentido para los Intillagtas la Chagra, como huerta integral juega un papel fundamental para el diario vivir de la comunidad, ahí se cultiva una variedad de especies agrícolas, como: maíz, fríjol, arracacha, arveja, cebolla, plantas medicinales y árboles frutales.

\section{Vivencias ancestrales de la comunidad}

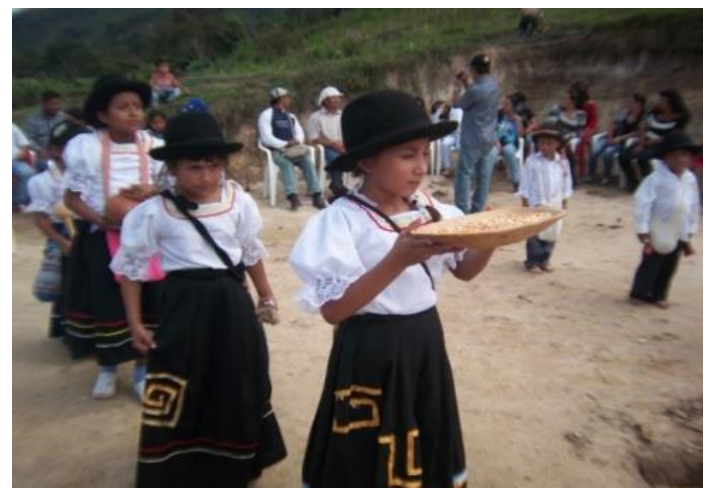

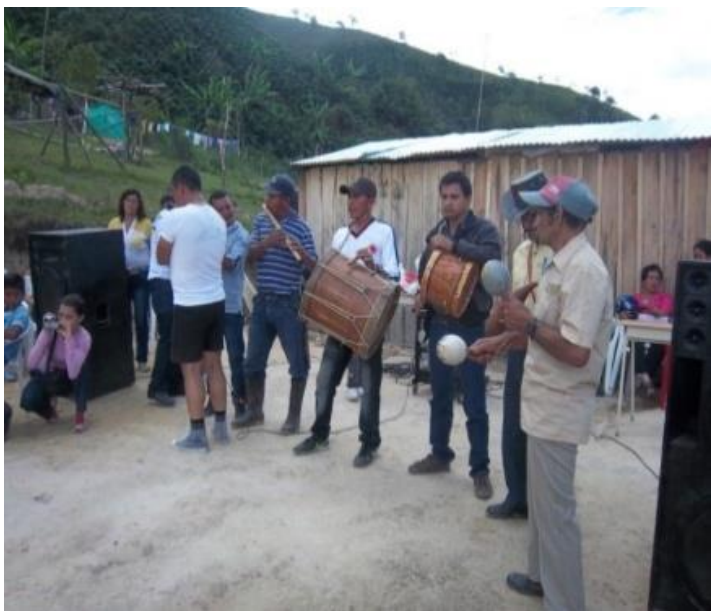

Los Intillagtas como pueblo Yanacona, dentro de los propósitos ancestrales plantean la resignificación cultural, en tanto que las nuevas generaciones vienen desempeñando un papel protagónico en la recuperación cultural, sobre todo en lo relacionado con la cosmovisión, símbolos, la recuperación del idioma originario, las costumbres y las prácticas espirituales y materiales. Ellos como comunidad tienen claro, que este proceso lo deben hacer con amor, con sentido identitario y con mucho compromiso, teniendo como soporte la cosmovivencia $\mathrm{y}$ las costumbres de los mayores $\mathrm{y}$ comunidad en general.

\section{Pueblo Misak}

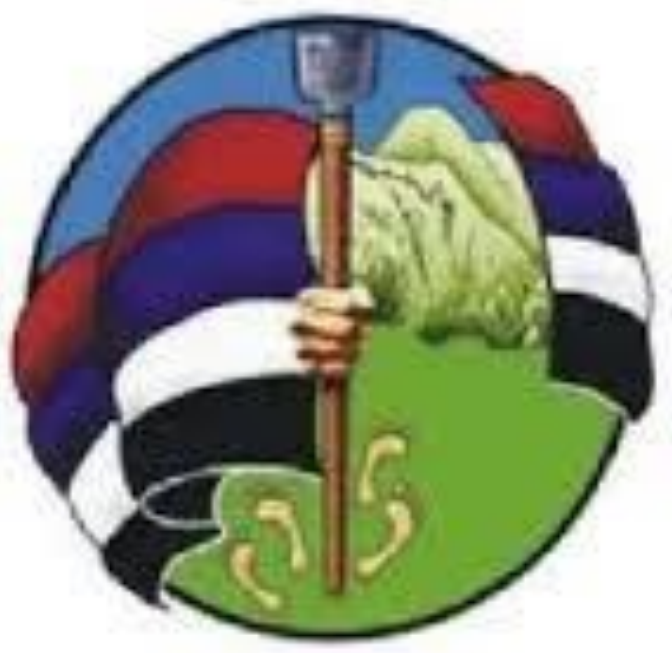




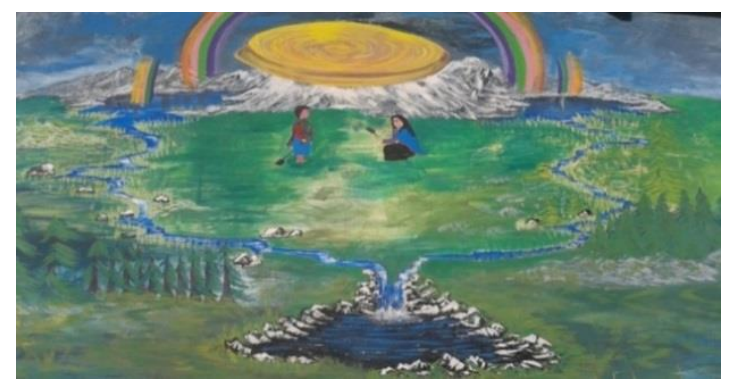

El pueblo Misak, es uno de los tantos pueblos originarios de nuestra América, que a la fecha han logrado pervivir, a pesar del maltrato y la idea de opresión y exterminio, que trajo la colonización; $\mathrm{Al}$ igual que todos los pueblos indígenas, existe junto a la naturaleza, una cosmovisión representada desde su origen; La perspectiva y proyección del pueblo Misak según Roberto Carlos Tombé, es "pervivir, permanecer en el tiempo de acuerdo a las costumbres, compartiendo la tierra, los alimentos y cosechas, vivir en comunidad y en convivencia con otras culturas, pero defendiendo la naturaleza, el territorio y los saberes ancestrales para vivir culturalmente como Misak" ", situación que proporciona una visión integral, entendiendo que antes de la colonia, el territorio latinoamericano estaba integrado por naciones indígenas, con diversas culturas, que hoy se encuentran amenazadas.

A través de la historia, el pueblo Misak ha creado su cosmovisión, pensamiento y desarrollo político y organizativo en cuanto al derecho a la tierra, a la justicia, a la educación, a la salud, a desarrollar la lengua materna y sus costumbres. Todo acompañado de lucha y resistencia, "y así caminando con mucho esfuerzo llegamos a la constituyente y allí logramos que reconocieran nuestros derechos, los

\footnotetext{
${ }^{1}$ Comentario realizado por Roberto Carlos Tombé, ex gobernador, durante una entrevista realizada en el resguardo Nuevo Amanecer de La Argentina Huila.
}

derechos de los indígenas" (Tunubalá, 2008, p. 12).

... los mayores hablan que primero fue la tierra y junto con ella estaba el agua. En el kөrrak o páramo había grandes lagunas, entre ellas Nupisu o Piendamu $\mathrm{m} \theta \mathrm{k}$ (macho) y Ñimpi ishukpisu (hembra); había humedales o ciénagas que se unieron con las lagunas y lo llamamos pikap-ojo de agua y todos se iban uniendo para formar dos ríos grandes que corrían hacia abajo, donde se unen para dar origen al piurek, que se llamó tata Illimpi y mama Keltsi, su esposa. Luego nacen los primeros hijos, ocupando diferentes espacios del territorio, unos habitando en $\operatorname{kausr} \theta$, otros en anistrapu y en wampiksr $\theta$; ellos fueron los shurmera, los mayores, de allí nacen los hombres y mujeres grandes como Piendamú, Calambás, Tumpe, Tesha de la Estrella, Karamaya, Manuela y Dominga, de ellos venimos todos los Misak, de ellos nacen todos nuestros valores y costumbres, y con ellos se rigen los destinos del territorio (Tunubalá \& Muelas, 2008).

El taita Antonio Tombé, comenta que "nace por la iniciativa de la familia Tombé, debido a la situación sobre la tenencia de tierra, nos organizamos como familia para comprar la finca en estas tierras, pero debido a la situación económica no se pudo, buscamos otros medios formando el cabildo en el año 1995 en ese entonces se integró, con otras que estaban en la misma situación que nosotros, como nuestros mayores tenían experiencia en la compra de tierras en el municipio de la Argentina y La Plata, los mayores, nos dijeron que acá habían buenas tierras, así llegamos a La Argentina, en el mismo instante iniciamos contacto con INCORA y hablamos con el 
alcalde, pues con la cooperación de ellos, surgió el resguardo Nuevo Amanecer".

\section{Diario vivir del Misak en el resguardo Nuevo Amanecer.}

De acuerdo a conversaciones y lecturas, se puede decir que el Misak, se caracteriza por actividades agrarias y comerciales; sin embargo los lugares donde habitan, no les garantizan ni posibilita condiciones básicas para vivir como comunidad:

Los indígenas de la Región Andina, vivimos en minifundio, en suelos de ladera y en ecosistemas frágiles, que no nos garantiza la producción de alimentos suficiente para vivir como gente, por eso, el pueblo Misak por derecho propio, optamos como política la reivindicación de los espacios que conformaron el hábitat de nuestros antepasados, para garantizar a las familias Misak, un espacio de tierras productivas, donde vivir y la reproducción de sus formas de vida. Pero no como un simple requerimiento económico, sino como la raíz de las costumbres, porque para los Misak la tierra no nos pertenece, sino que nosotros pertenecemos a la tierra (Tunubalá \& Muelas, 2008, p. 98).

Sin embargo la actividad cotidiana, según el profesor Samuel, es "Trabajar para la comunidad, para fortalecerla y vivir pensando en la familia Misak; viviendo atento de cómo será el mañana para nuestros hijos en este mundo tan descontrolado".

\section{Motricidad humana}

\section{Expresiones motrices}

Como manifestación del ser humano, para reflexionar, sentir y compartir de forma intencionada a través de esa relación infinita con el mundo y su devenir, trascienden el impulso emocional, para transformase en conexión, donde se conjuga historia, cultura, deseos, sentimientos, anhelos, sueños y todos los demás colores que conforman nuestro arcoíris humano en acciones que nos hace ser más humanos. En este sentido las expresiones motrices lúdicas, deportivas, artísticas y ecológicas aportaron elementos valiosos para comprender las realidades vividas por las comunidades originarias.

\section{Expresiones Lúdicas}

Los Misak del resguardo El Nuevo Amanecer, pueblo sonriente como el sol que les alumbra y alimenta el mundo cada día. Este es un pueblo que goza y sonríe como muestra de esperanza respirando lucha, esa lucha que les da paso y abre caminos a su existencia. Manifiestan que "las expresiones lúdicas tienen un gran significado, como es el de aprovechar el tiempo que nos queda libre a pesar de que al pueblo Misak casi no le queda tiempo pero el que queda se aprovecha a través del juego. Para nosotros el juego, es diversión, significa compartir, vivir en armonía, y comunidad". Es evidente la trascendencia que tienen las expresiones lúdicas en la vida de la comunidad Misak como espacio de amor, solidaridad, placer y felicidad.

Para el pueblo Yanacona, representado en el cabildo Intillagta, las expresiones lúdicas tienen gran significado por lo cual le atribuyen; “el despertar el espíritu de 
runa (persona), aprendizaje, alegría y armonía con el entorno. Se desarrolla de manera integral donde participan niños, jóvenes, adultos y toda la comunidad en general la cual representa la unidad, colectividad $\mathrm{y}$ hermandad del pueblo Yanacona".

\section{Expresiones Artísticas}

Las expresiones artísticas, pueden ser sentidas como una de las formas más puras del ser humano en el mundo, pues en ellas se armonizan intensamente sentimientos y sentidos de estar, vivir y ser en el mundo en conexión con los colores que como seres nos adornan y que se configuran en la creación. Es por ello que como expresiones humanas tuvieron significado en el presente estudio como develación de la realidad de las comunidades Misak y Yanacona del departamento del Huila.

La comunidad Misak con relación a sus expresiones artísticas, develaron con gran sentido de pertenencia que "son acciones que expresamos a través de la música, de cantos y algunas danzas, pues a través de ellas damos a conocer las diferentes maneras de expresar lo que es el sentir con la naturaleza, con uno mismo y valorar lo que hacemos y qué es lo que tenemos que hacer en nuestros procesos; en cuanto a la participación en las expresiones artísticas, pues hay saberes ancestrales, desde nuestros mayores y los médicos tradicionales quienes son un punto de vista en donde ellos son quienes hacen los rituales, y sus quehaceres al interior de la comunidad".

La comunidad Yanacona, posee una riqueza de expresiones artísticas que no solo seduce, sino que también hacen sentir un renacer en ellas. Para comprender esto es necesario acercarnos a sus voces, quienes con firmeza expresaron: "as expresiones motrices artísticas construyen de forma alegre, creativa y sonriente; historia, identidad, lucha, cosmovisión, fuerza y resistencia, y por ello son trascendentales para la supervivencia cultural".

\section{Expresiones ecológicas}

A manera de reflexión, aparecen las expresiones motrices ecológicas, como un renacer, un avatar que nos convierte en una única energía, que evita ver a la naturaleza como un algo inferior, y bajo nuestro poder creemos profundamente que debemos mudar de esa naturaleza como objeto, en donde a través de la corporeidad se vivencie el amor en el sentirnos en conexión eterna y conjugada, entendiéndonos en un compartir pensándonos todos, del cual somos como el arcoíris, colores diversos pero si un arcoíris, un mundo.

Los Misak asumen las expresiones ecológicas como; "relaciones muy significativas, pues somos hijos del agua, hijos de la tierra, ella es nuestra madre que nos da la vida, nos da de comer, por eso nosotros la amamos y cuidamos mucho, por eso le decimos a la sociedad que hay que aprender a cuidarla, porque de ella venimos y por ella vivimos; ahora nosotros no decimos naturaleza o medio ambiente nosotros hablamos de ambiente de vida; porque el pueblo Misak todo tiene vida".

Desde lo hallado, para los Yanaconas las expresiones motrices ecológicas representan un espacio significativo para la construcción de su pueblo; por ello, son "las más importantes, pues ellas son generadoras de vida, en donde el runa Yanacona tiene la oportunidad de poder convivir y comunicarse constantemente a 
través de los espíritus sagrados; y la relación que existe entre hombrenaturaleza sin desconocer que $\sin$ la tierra, el agua, la flora y la fauna no podemos vivir".

\section{Expresiones deportivas}

En el mundo de las comunidades originarias las expresiones motrices deportivas tienen una amplia representación en su realidad y vida; aunque reconocen que las expresiones deportivas del norte están cargadas de consumismo, de esencia bélica y de irrespeto por la complejidad.

Los Misak afirman; que "el significado del deporte depende de cómo sea utilizado, para nosotros ambos son importantes, pues el deporte de occidente, no podemos decir que es malo y que debe ser desechado, pues en su esencia encontramos una forma de integrarnos. Por ejemplo, un sábado o domingo que hay encuentro de fútbol salen las mujeres, los hombres, los niños, apoyando a su equipo, de igual manera ocurre en un juego tradicional, como el zarampico que es un juego propio de la comunidad Misak".

Para la comunidad Yanacona, las expresiones motrices deportivas son; "una vivencia sana que permite el desarrollo físico-mental de la persona y un espacio muy significativo para la convivencia intercultural. Pero se debe estar atentos ante el deporte de occidente pues este ha venido invadiendo nuestra cultura, todos los jóvenes, niños y aun los adultos quieren jugar fútbol siempre, y ya muy poco al cuy, la vaca loca y la chaza, esto es una pequeña evidencia de su invasión".

\section{Corporeidad}

\section{Sentidos de cuerpo}

Qué inverosímil es respirar y vernos unos a otros, vernos a los ojos convencidos de creer justamente lo que somos, de creer que ese color de ojos, de cabello de piel y de ser, en sí todo lo que nos conjuga como seres ha sido siempre nuestro. Vaya sorpresa nos llevamos al reflexionar en nuestra profundidad $\mathrm{y}$ acercarnos a nuestro descubrimiento, en donde aquel firme convencimiento con el que nos veíamos, pasa a ser efímero.

Iniciaremos con la comunidad Misak, quienes al dialogarnos sobre su sentido de cuerpo expresaron: "es importante para la vida, es con el que nosotros podemos responder a cualquier acto físico, de trabajo, deporte o cualquier otro, por eso es importante enseñarle a nuestros hijos como cuidarlo, amarlo y respetarlo a través de la alimentación y el deporte; es por ello que practicamos el juego tradicional y hacemos ejercicio, porque de ahí el cuerpo se vive, es nuestro pensar, es nuestra vida". Según lo relatado el cuerpo tiene una gran incidencia en su diario vivir y en la construcción de su identidad como comunidad y pueblo originario.

Entraremos a divisar desde las voces de la comunidad Yanacona, sus sentidos de ser cuerpo, en donde se encontró un sentido que manifiesta la relación con la esencia de la génesis de su pueblo. De esta forma para los yanaconas cuerpo; "representa los tres momentos de vida del runa yanacona como el uku pacha, kay pacha y hananpacha".

Las comunidades originarias, rechazan el cartesianismo que redujo y fragmentó el cuerpo, porque, según ellos, caminan 
sobre un sentido de hombre como "unidad compleja que contiene en si misma distintas dimensionalidades a través de las cuales se manifiesta y desarrolla, no en forma aislada sino por el contrario cada dimensionalidad afecta a la otra" (Sérgio \& Toro, 2005).

\section{Vivencias corpóreas}

Al ser testigos de las vivencias corpóreas de las comunidades originarias, comprendimos su cosmovisión y formas de ser, estar y vivir el mundo. En donde también toma gran importancia la voz de los actores que fueron escuchadas a través de entrevistas.

Para la comunidad Misak tiene sentido gran variedad de vivencias corpóreas como expresión encarnada y orientada al mantenimiento del diálogo y la armonía con el mundo. En su voz, el Gobernador dice: "El caminar Misak, el cómo caminamos, para dónde caminamos. Nuestro caminar nos identifica. El caminar hacia el futuro y caminar hacia el pasado, porque el pasado no ha pasado del todo y no se ha acabado, tenemos que enrollar y desenrollar para llegar al mismo ombligo donde nosotros hemos nacido; por eso el caminar es algo significativo para nosotros".

Para los Yanaconas, las vivencias corpóreas hacen parte de su diario vivir, pues a través de ellas construyen la supervivencia de su comunidad en el mundo capitalista y neoliberal que amenaza su extinción. Ante ello el profesor durante la entrevistas comentó que; "las vivencias expresadas por la comunidad se encarnan en la danza los juegos tradicionales y la ejercitación de la guardia indígena".
El sentido de vivencias otorgado por las comunidades originarias se encuentra tan cercano a la realidad que actualmente respiramos, esa realidad que pretende consumirlos y transformarlos en instrumentos desposeídos de color y diversidad, lo cual es el proyecto de la ola neoliberal y homogeneizadora que a través de múltiples acciones "maquilladas por el poder, el cual históricamente ha querido al cuerpo fuerte, más dócil, sumiso, obediente a sus órdenes e intereses (Foucault, 1963).

\section{Tejido social}

El tejido social se comprende como "un proceso de participación, integración y comunicación para buscar bienestar a nivel individual y colectivo, de tal forma que contribuya al desarrollo comunitario y a mejorar la calidad de vida de un grupo de personas que trabajan por el bien común, con el propósito de desarrollar valores relacionados con la autonomía, solidaridad, identidad $y$ sentido de pertenencia" (Bahamón C. Pablo Emilio, 2010, p. 38).

En este sentido, hablar de tejido social, es reconocer todo el proceso de decolonialidad que vienen ejerciendo las comunidades indígenas de América Latina y de Colombia para fortalecer sus luchas y actos de resistencia, que conducen a recuperar y defender su territorio, su cosmovisión y su cultura ancestral como comunidades originarias libres y autónomas. Porque hay que recordar que los indígenas después de la colonización española han sido víctimas de las políticas del occidente proyectadas por el neoliberalismo salvaje. Situación que certifica Eduardo Galeano cuando dice: "La experiencia indica que es la amnesia la que hace que la historia se repita y que se repita como pesadilla. $\mathrm{La}$ 
buena memoria permite aprender del pasado, porque el único sentido que tiene la recuperación del pasado es que sirva para la transformación de la vida presente" (Galeano, 1996).

Para continuar fortaleciendo el estado del arte del tejido social, el grupo de investigación MOLÚFODE ha considerado necesario continuar profundizando sobre los procesos de participación, autonomía, organización, democracia y de resistencia.

La participación es un acto democrático, que posibilita el hacer parte en la toma de decisiones; debe ser comprendida como un proceso que busca desde la colectividad satisfacer necesidades que fomentan el bienestar y la calidad de vida del ser humano y la comunidad en general. Desde esta perspectiva la participación para las comunidades originarias es un proceso de trasformación social y cultural que tiene un alto grado de integración simbólica y de cosmovisión que posibilita expresar decisiones y fortalecer los espacios de organización, democracia y resistencia.

La autonomía para las comunidades originarias del Huila, comprende el desarrollo humano y la toma de decisiones, donde se incluye la toma de consciencia como elemento fundamental en la transformación personal y social, de tal manera que promueva la prosperidad, la vocación y la sabiduría para tomar las decisiones consciente pensando en el cabildo y en sus sistemas de organización, que tienen como propósitos la libertad y amor por su cultura ancestral; en este sentido se comparte con Paulo Freire, cuando plantea que "la autonomía es un proceso continuo de construcción. El ser humano no la conquista definitivamente porque ésta forma parte de la inclusión de los hombres y en la consciencia que de ella tienen, colocándose en una nueva conquista necesaria para la superación de aquello que le impide ser libre conscientemente" (Saúl, Ana María, De Mesquita, Delma Lucía, 2002, p. 91).

El grupo de investigación MOLÚFODE en sus diferentes estudios, ha asumido la organización como un "proceso formativo que desarrollan las personas y los grupos para tomar conciencia sobre las necesidades comunitarias, y se manifiesta a través de la solidaridad, el liderazgo, la participación y la democracia. Por consiguiente, las organizaciones son unidades sociales deliberativas, que persiguen objetivos y acciones que establecen responsabilidades para ejercer funciones de acuerdo a los compromisos adquiridos" (Bahamón C. Pablo Emilio, 2010).

La organización para los indígenas es el espacio donde se busca fortalecer procesos políticos y organizativos desde las bases para la pervivencia y la convivencia como pueblos originarios; en esta medida existen organizaciones como: el (CRIHU) Consejo Regional Indígena del Departamento del Huila; (CRIC) Consejo Regional Indígena del Departamento del Cauca y (ONIC) Organizaciones Nacionales Indígenas de Colombia.

Dentro de las formas de organización interna de las comunidades originarias en el Huila destacamos las siguientes:

1. La minga

2. La asamblea

3. La guardia indígena

Es importante destacar que las organizaciones tienen como objetivos: "recuperar las tierras de los resguardos, 
fortalecer los cabildos indígenas; no pagar terraje; difundir las leyes sobre indígenas y exigir su justa aplicación; defender la historia, la lengua y las costumbres indígenas; formar profesores indígenas para educar de acuerdo con la situación de su pueblo y en su respectiva lengua" (Ministerio de Cultura de Colombia, 2010).

La organización mantiene la convivencia y ayuda a buscar estrategias para recuperar el territorio y la cultura ancestral; porque la unidad y la lucha es el camino para descolonizarse y recuperar lo usurpado. Postulados que profundiza Trigo cuando dice: "divide y vencerás" tan en boga en el mundo institucional y empresarial del capitalismo es muy malo, porque eso impide crecer, caminar en los horizontes y sentirnos gratificados con los resultados que entre todos obtenemos" (Trigo y Montoya, 2009, p. 88).

En consecuencia, asumiendo el concepto de Morín, "La democracia es un sistema complejo de organización y de civilización política que alimenta y se alimenta de la autonomía de espíritu de los individuos, de su libertad de opinión y de expresión, de su civismo que alimenta y se alimenta del ideal, Libertad <-> Igualdad <-> Fraternidad, el cual comporta un conflicto creador entre estos tres términos inseparables" (Morin, 1999).

La democracia para las comunidades originarias es un proyecto de convivencia, de fraternidad, de respecto, de relación y de toma de decisiones entre los miembros del cabildo; por eso como derecho y como ejercicio educativo y creativo se viene fortaleciendo permanentemente en cada una de sus organizaciones reconocidas por la comunidad.
Para las comunidades indígenas "la democracia es asumir unos compromisos y unos mandatos como autoridades de forma transparente con un solo propósito que es el bienestar de los pueblos, teniendo en cuenta que la pervivencia está basada en la buena acción de los líderes. Se aplica la democracia en las mingas de pensamiento, en los planteles educativos en la elección de líderes".

Los postulados anteriores los refuerza Willem Assies, Gemma van der Haar y André J. Hoekema en su texto, Los pueblos indígenas y la reforma del Estado en América Latina cuando dicen:

"Si bien el desarrollo de nuevas formas de participación y democracia indígena en el interior del Estado y sus instituciones es un aspecto importante del nuevo pluralismo, el respeto para con la autonomía de las instituciones indígenas constituye el otro componente crítico. Conjugar estos dos rasgos es lo que representa el desafío más serio, pues implica una extensa reforma de las actuales estructuras del Estado y una revisión de los conceptos en que se basa. Es aquí donde hay que encarar el pluralismo en el sentido de la "autodeterminación interna" y del reconocimiento y acomodo de los derechos colectivos" (Willem Assies, 1999).

Por otro lado la resistencia de las comunidades indígenas colombianas, ha sido un proceso identitario de los pueblos para defender su cultura y su territorio, usurpado por los españoles y por los grandes terratenientes que mediante actos de violencia han venido invadiendo territorial y culturalmente, por eso ellos tienen muy claro no dejarse avasallar por fuerzas dominantes que buscan ilegitimar y pisotear su cosmovisión. 
Históricamente representa una acción que ha estado presente en todos los momentos de las comunidades indígenas, ellos a través del acto de resistir han dado hasta su vida por la defensa de sus derechos, su historia, su lengua ancestral, su cosmovisión y las costumbres indígenas. En este sentido, Juan de Castellanos señala en términos generales, que los pueblos indígenas por defender su cultura el miedo de morir es lo de menos.

\section{Conclusiones}

- Las representaciones e imaginarios de las comunidades indígenas en el departamento del Huila Sur de Colombia, se materializan a partir de expresiones corpóreas y motrices que proyectan el desarrollo ideológico de su cosmovisión desde diferentes perspectivas, que enmarcan la identidad cultural y el territorio como elementos centrales de la cosmogonía de las comunidades indígenas latinoamericanas; así como los desarrollos particulares de las comunidades indígenas del Huila y Colombia, en las que se particularizan las características relacionadas con la política, la economía, la ecología, la lengua, las costumbres y la preservación cultural, como dimensiones que ayudan a precisar la interacción yo, otros y cosmos.

- La perspectiva y proyección de los pueblos indígenas en Colombia, es pervivir, permanecer en el tiempo de acuerdo a las costumbres, compartiendo la tierra, los alimentos y cosechas, vivir en comunidad y en convivencia con otras culturas, pero defendiendo la naturaleza, el territorio y los saberes ancestrales para vivir culturalmente como comunidades originarias identitarias y defensoras de las amenazas impuestas por el neoliberalismo y la cultura del occidente.

- Es importante destacar que las comunidades originarias asocian el hecho de tener la autonomía en el propio cuerpo, en tanto se debe saber qué hacer con él y cómo cuidarlo y manejar el significado de territorialidad, ante las diferentes formas físicas que se dan durante el contacto con la naturaleza.

- Las vivencias corpóreas rituales como expresiones encarnadas y orientadas al mantenimiento del diálogo y la armonía con el mundo, promueven el vivir en equilibrio y en paz, bajo el cuidado de los médicos tradicionales, buscando evitar enfermedades que puedan llegar a afectar a las comunidades. Es muy importante creer en la naturaleza, por eso se debe valorar, respetar y fortalecerla día a día.

- Las comunidades indígenas del Huila vienen funcionando como cabildos y resguardos y se encuentran en un proceso de articulación y trabajo en función de recuperar sus costumbres y tradiciones; fortaleciendo sus organizaciones, estimulando su cultura y buscando mecanismos para recuperar socialmente el territorio usurpado. 
- Las comunidades originarias a partir de sus formas de organización, luchan y resisten permanente, para construir formas particulares de educar, teniendo en cuenta prácticas pedagógicas ligadas a un discurso compartido acerca de la naturaleza de los seres humanos, sus capacidades y su relación con el mundo y los otros; por esto se buscan escenarios revalorados $\mathrm{y}$ determinados por las características propias, la cosmovisión de las comunidades indígenas del sur de Colombia.

- Hablar de ecología con las comunidades indígenas, es recortar o limitar las posibilidades para plantear el universo que hace parte de su cosmovisión y su cultura, en tanto uno de los fines indígenas es garantizar el derecho natural de la naturaleza, en la búsqueda del hombre por la defensa de la felicidad, disfrute, armonía y equilibrio físico, espiritual y mental, es inmutable por ser parte de la identidad cultural.

- El tejido social ha sido una acción que busca el unir intereses individuales $y$ con el fin de proyectarlo a los intereses colectivos, tratando de resolver las necesidades del desarrollo humano desde una mirada integral y sostenible. Por consiguiente, el tejido social, debe proyectarse a la formación de personas críticas y conscientes capaces de interactuar de manera asertiva con su colectividad.

\section{Bibliografía}

Acevedo Linares, A. (13 de diciembre de 2001).http://www.monografias.com/tra bajos11/tole/tole.shtml. Obtenido de http://www.monografias.com/trabajos 1 1/tole/tole.shtml.

Arboleda Gómez, R. (2008). Las expresiones motrices, una representación hacia la configuración del campo académico.

Bahamón Cerquera Pablo Emilio, C. S. (2010). La motricidad: estrategia para construir y reconstruir tejido social. Neiva: Universidad Surcolombiana.

Barreto Callamad, R. F. (23 de septiembre de 2008). Instituto de Investigación y Debate sobre la Gobernanza. Obtenido de http://www.institutgouvernance.org/es/analyse/ficheanalyse-392.html.

D'aubeterre, L. (2003). Ciudad, discursividad, sentido común e ideología: Un enfoque psicosocial de la cotidianidad urbana. Redalyc.org (Red de Revistas Científicas de América Latina, el Caribe, España y Portugal), 169-186.

Enciclopedia cubana virtual Ecured. (4 de mayo de 2012). http://www.ecured.cu/index.php/Identi dad_cultural.

Estupiñan Quiñones, N. y. (25 de abril de 2012).http://redalyc.uaemex.mx/pdf/86 9/86901003.pdf.

Galeano, E. (1996). La memoria subversiva. Tiempo: reencuentro y esperanza. 
Klefbeck, J. (1999). Redes el lenguaje de los vínculos. Buenos Aires: Pardos Ideas.

Kon-moción, Grupo de Investigación. (2008). Motricidad humana y gestión comunitaria. . Universidad del Cauca.

López Parra, H. J. (2002). Investigación cualitativa y participativa.

Ministerio de Cultura de Colombia. (s.f.). http://www.mincultura.gov.co/areas/po blaciones/noticias/Documents/Caracter izaci\%C3\%B3n\%20del\%20pueblo\%2 0Yanacona.pdf. Obtenido de http://www.mincultura.gov.co/areas/po blaciones/noticias/Documents/Caracter izaci\%C3\%B3n\%20del\%20pueblo\%2 0Yanacona.pdf.

Ministerio de Cultura, R. d. (Enero de 2010). Compendio de Políticas Culturales, , Primera edición.

Molano, O. L. (Mayo de 2007). Redalyc.org. Obtenido de http://www.redalyc.org/articulo.oa? $\mathrm{id}=$ 67500705.

Organización Internacional del Trabajo. (2009). Trabajo infantil y pueblos indígenas en América Latina. Una aproximación conceptual. Lima.

Palechor Jiménez, E. (21 de diciembre de 2001). http://www.mininterior.gov.co/sites/def ault/files/plan_de_vida_yanacona.pdf. Recuperado el 2013, de http://www.mininterior.gov.co/sites/def ault/files/plan_de_vida_yanacona.pdf.

Reynaga Burgoa, R. (2007). Tawa Inty Suyu. Lima.
Rodriguez, G. y. (Mayo de 2012). Métodos de la investigación cualitativa. Obtenido de www.asesoriasdosmil.com/espdoc/epis temologia/Lectura_6.swf.

Saúl, Ana María, De Mesquita, Delma Lucía. (2002). Paulo Freire y la Formación de Educadores, Múltiples miradas (Primera ed.). Buenos Aires, Argentina: Siglo Veintiuno editores.

Trigo Eugenia y Montoya Harvey. (2009). Motricidad Humana: política, teoría y vivencias. España-Colombia: Léeme.

Trigo, E. y. (2000). Manifestaciones de la motricidad. Editorial Inde.

Trigo, E. y. (Editorial universidad del cauca. 2005, Pág. 102. de 2005). Enacción Consentido. Popayán: Editorial universidad del Cauca.

Tunubalá, f. y. (2008). Segundo plan de vida de pervivencia y crecimiento Misak. Guambia: digitos y diseños.

Tunubalá, F., \& Muelas, J. (2008). Segundo plan de vida de pervivencia del pueblo Misak. Guambia: digitos y diseños.

Wikipedia.org. (s.f.). http://es.wikipedia.org/wiki/Pueblo_Ya nacona\#cite_note-2. Recuperado el 10 de 12 de 2013, de wikipedia: http://es.wikipedia.org/wiki/Pueblo_Ya nacona\#cite_note- 2 .

Wilches Chaux, G. (2005). Proyecto Nasa: la construcción del plan de vida de un pueblo que sueña.

Willem Assies, G. V. (1999). Los pueblos indigenas y la reforma del estado en América Latina. México. 